\title{
Estrogen Pharmacology. I. The Influence of Estradiol and Estriol on Hepatic Disposal of Sulfobromophthalein (BSP) in Man*
}

\author{
Mark N. Mueller $\dagger$ and Attallah Kappas $\ddagger$ with the technical assistance \\ of Evelyn Damgaard \\ (From the Department of Medicine and the Argonne Cancer Research Hospital, $\S$ the \\ University of Chicago, Chicago, Ill.)
}

This report ${ }^{1}$ describes the influence of natural estrogens on liver function, with special reference to sulfobromophthalein (BSP) excretion, in man. Pharmacological amounts of the hormone estradiol consistently induced alterations in BSP disposal that were shown, through the techniques of Wheeler and associates $(2,3)$, to result from profound depression of the hepatic secretory transport maximum $(\mathrm{Tm})$ for the dye. Chromatographic analysis of plasma BSP components revealed increased amounts of BSP conjugates during estrogen as compared with control periods, implying a hormonal effect on cellular processes concerned with transport of dye from hepatocytes into biliary canaliculi. Estriol, an in vivo transformation product of estradiol, also impaired hepatic disposal of BSP in man. According to unpublished data of Hertz (4) ${ }^{2}$ estrone, ethinyl estradiol, and equine estrogens act similarly, and it is likely that other C-18 steroids of both physiologic and synthetic origin have this property as well. These observations define a new

* Submitted for publication April 13, 1964; accepted June 16, 1964.

$\dagger$ Present address: Department of Microbiology, Yale University School of Medicine, New Haven, Conn.

$\ddagger$ Address reprint requests to: Dr. A. Kappas, Department of Medicine, The University of Chicago, Chicago, Ill. 60637.

$\S$ Operated by the University of Chicago for the U. S. Atomic Energy Commission.

1 These data were presented at the 77th Annual Meeting of the Association of American Physicians, May 6, 1964 , and a preliminary report was published in the Transactions of that society (1).

$2 \mathrm{We}$ have recently been privileged to review earlier unpublished observations of Dr. Roy Hertz, National Cancer Institute, on BSP metabolism in cancer patients undergoing intensive estrogen therapy. These observations demonstrate rapid and consistent abnormalities in BSP disposal, as described in this report. biological action of natural estrogens in man, further substantiate the role of the liver as a site of action of these hormones (5), and probably account, in part, for the impairment of BSP disposal that characterizes pregnancy (6) and the neonatal period $(7-10)$.

\section{Methods}

Steroid solutions were prepared by dissolving crystalline estradiol and estriol in a solvent vehicle containing $10 \%$ N,NDMA $(N, N \text {-dimethylacetamide })^{3}$ in propylene glycol. Estradiol was soluble in a concentration of 100 $\mathrm{mg}$ per $\mathrm{ml}$; estriol, in a concentration of $20 \mathrm{mg}$ per $\mathrm{ml}$. These, together with appropriate control solutions, were sterilized by filtration at room temperature and administered to patients by intramuscular injection. All subjects were housed on a metabolic ward during the study, and a number were maintained on fixed diets as required by concurrent investigations. The principal clinical diagnoses were rheumatoid arthritis and related connective tissue disorders. The observations reported here were made during a series of studies designed initially to examine the potential use of pharmacological amounts of natural estrogens as therapeutic or immunosuppressive (11-13) agents in man; the periods of estrogen administration therefore varied considerably from subject to subject. Liver function was examined in these patients by the following tests: per cent esterification of cholesterol, direct and indirect bilirubin, cephalin and thymol flocculations, thymol turbidity, prothrombin time, serum albumin and globulin, retention of BSP in plasma $45 \mathrm{~min}-$ utes after intravenous administration of $5 \mathrm{mg}$ per $\mathrm{kg}$ body weight, and the following serum enzymes: alkaline phosphatase, lactic dehydrogenase (LDH), glutamic pyruvic transaminase (SGPT), and glutamic oxaloacetic transaminase (SGOT). BSP infusion studies, chromatography of plasma BSP components, and liver biopsies were performed in several subjects as described below.

Thirty-one patients were treated with either estradiol or estriol. Two were males and 29 were females, most of whom were postmenopausal. Estradiol was adminis-

\footnotetext{
${ }^{3}$ Eastman Organic Chemicals, Division of Eastman
} Kodak Co., Rochester, N. Y. 
tered to 25 patients ( 24 female) in amounts of 5 to 200 $\mathrm{mg}$ per day for 3 to 41 days. Estriol was administered to 6 patients ( 5 female) in amounts of 7 to $40 \mathrm{mg}$ per day for 6 to 10 days. Injections of control vehicle solutions were given to each of 13 patients in amounts of $2 \mathrm{ml}$ per day for 30 days.

\section{Results}

Liver function tests were performed twice in control periods in all subjects and at frequent intervals during control injections and estrogen treatment.

Control vehicle-treated subjects. No alterations in any liver function test were detected in the 13 control patients either during the 4-week treatment period or in the succeeding 3 months. N,NDMA does produce some hepatotoxicity in experimental animals when given in doses greatly exceeding those employed in this study $(14,15)$; however, this substance is approved for use clinically as a solubilizing agent for antibiotics in a concentration of $50 \%$ and no hepatotoxicity has, to our knowl- egde, been reported. The studies of Hertz (4) that were done with aqueous or other estrogen preparations in any case obviate the possibility that BSP impairment reported here is related to solvent vehicle action.

Estrogen-treated subjects. The 31 patients in this group were selected on the basis of normal hepatic function with particular reference to BSP retention ( $6 \%$ or less in 45 minutes), alkaline phosphatase (6 Bodansky U or less), bilirubin, and appropriate serum enzymes during control periods.

The following tests remained unchanged from control values in all subjects during estrogen treatment and in follow-up periods ranging from 3 to 12 months: cephalin and thymol flocculations, thymol turbidity, per cent esterified cholesterol, prothrombin time, direct and indirect bilirubin, $\mathrm{LDH}$, SGOT, and SGPT. Total serum proteins showed changes consistent with estrogen-induced plasma volume increases, but albumin to globulin ratios

TABLE I

Treatment schedule, sulfobromophthalein (BSP) tests, and serum levels of alkaline phosphatase during control and estrogen periods in 31 subjects

\begin{tabular}{|c|c|c|c|c|c|c|}
\hline \multirow[b]{2}{*}{ Patient } & \multirow{2}{*}{\multicolumn{2}{|c|}{ Treatment }} & \multicolumn{2}{|c|}{ BSP retention } & \multicolumn{2}{|c|}{ Alkaline phosphatase } \\
\hline & & & Control & Estrogen & Control & Estrogen \\
\hline & \multicolumn{2}{|c|}{$m g /$ day $\times$ days } & \multicolumn{2}{|c|}{$\%$} & \multicolumn{2}{|c|}{ Bodansky $U$} \\
\hline L.G. & Estriol & $7 \times 8$ & 1.7 & 7.2 & 3.0 & 3.0 \\
\hline J.Z. & Estriol & $10 \times 7$ & 2.2 & 4.7 & 2.9 & 4.7 \\
\hline O.H. & Estriol & $10 \times 9$ & 3.9 & 7.4 & 4.5 & 5.2 \\
\hline J.W. & Estriol & $20 \times 6$ & 1.7 & 2.0 & 2.5 & 2.0 \\
\hline E.O. & Estriol & $20 \times 8$ & 3.0 & 8.4 & 4.6 & 4.9 \\
\hline M.H. & Estriol & $40 \times 10$ & 4.7 & 9.4 & 4.6 & 6.6 \\
\hline J.R. & Estradiol & $5 \times 6$ & 1.0 & 2.8 & 2.5 & 3.0 \\
\hline R.B. & Estradiol & $5 \times 6$ & 2.4 & 7.7 & 4.2 & 7.7 \\
\hline E.M. & Estradiol & $5 \times 7$ & 2.7 & 10.6 & 6.0 & 9.6 \\
\hline E.C. & Estradiol & $10 \times 18$ & 3.3 & 7.2 & 4.6 & 4.4 \\
\hline O.H. & Estradiol & $25 \times 5$ & 4.4 & 9.7 & 3.2 & 4.0 \\
\hline S.T. & Estradiol & $25 \times 9$ & 4.8 & 10.8 & 5.0 & 4.8 \\
\hline P.D. & Estradiol & $25 \times 12$ & 4.9 & 11.0 & 4.3 & 4.3 \\
\hline C.T. & Estradiol & $50 \times 5$ & 3.9 & 9.4 & 4.8 & 15.3 \\
\hline D.H. & Estradiol & $50 \times 17$ & 3.1 & 11.0 & 4.2 & 3.8 \\
\hline L.T. & Estradiol & $100 \times 3$ & 4.2 & 15.0 & 5.3 & 15.4 \\
\hline C.M. & Estradiol & $100 \times 7$ & 2.8 & 10.2 & 4.2 & 13.0 \\
\hline E.K. & Estradiol & $100 \times 11$ & 3.6 & 17.2 & 2.5 & 2.3 \\
\hline V.S. & Estradiol & $100 \times 11$ & 3.4 & 13.3 & 3.6 & 12.1 \\
\hline B.P. & Estradiol & $150 \times 5$ & 2.0 & 14.1 & 4.2 & 6.0 \\
\hline M.S. & Estradiol & $200 \times 3$ & 5.4 & 13.6 & 5.0 & 4.5 \\
\hline E.B. & Estradiol & $200 \times 22$ & 6.0 & 23.3 & 3.9 & 6.3 \\
\hline A.T. & Estradiol & $200 \times 23$ & 5.0 & 22.9 & 3.9 & 5.2 \\
\hline A.S. & Estradiol & $200 \times 23$ & 4.5 & 7.8 & 4.4 & 3.6 \\
\hline W.C. & Estradiol & $200 \times 24$ & 5.4 & 13.7 & 4.7 & 9.0 \\
\hline G.S. & Estradiol & $200 \times 27$ & 2.8 & 9.6 & 4.5 & 3.8 \\
\hline J.K. & Estradiol & $200 \times 30$ & 3.0 & 10.0 & 3.9 & 8.1 \\
\hline H.E. & Estradiol & $200 \times 31$ & 5.0 & 30.0 & 2.5 & 5.1 \\
\hline L.M. & Estradiol & $200 \times 33$ & 4.0 & 8.8 & 2.7 & 12.2 \\
\hline M.L. & Estradiol & $200 \times 34$ & 5.8 & 11.3 & 5.2 & 6.4 \\
\hline E.L. & Estradiol & $200 \times 41$ & 4.1 & 17.0 & 5.3 & 8.8 \\
\hline
\end{tabular}




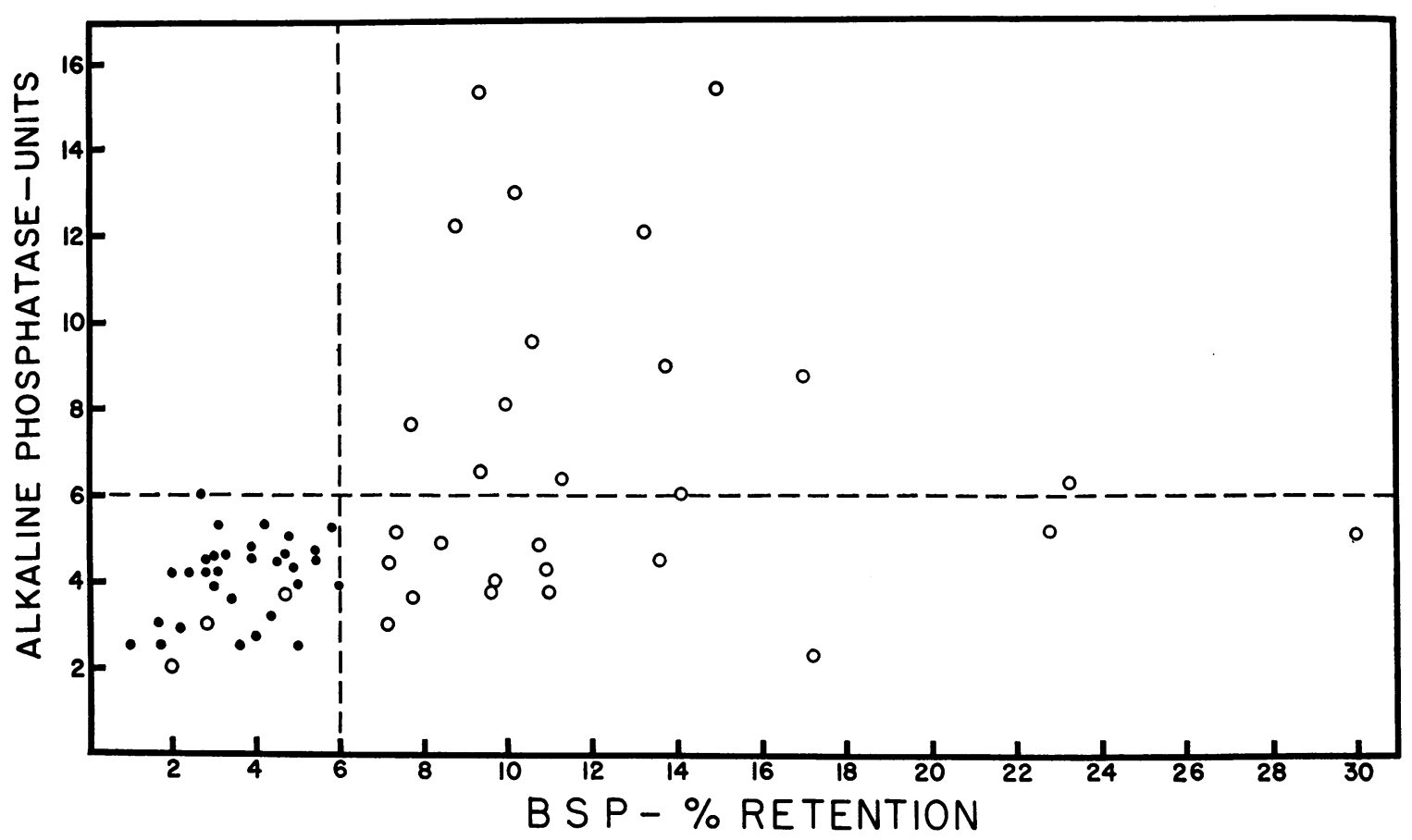

Fig. 1. Serum levels of alkaline phosphatase plotted against per Cent RETENTion of SUlfobromophthalein (BSP) DURING CONTrol and eStrogen Periods in 31 subjects. Control values are indicated by solid dots; estrogen period values by open circles. Normal values for both indexes are enclosed in the lower left quadrant.

were unaltered from control values. Serum alkaline phosphatase rose to abnormal levels (in excess of 6 Bodansky U) in nearly $50 \%$ of estrogentreated patients and remained elevated until injections ended. In this study BSP retention in plasma exceeding $6 \% 45$ minutes after injection of the standard dose ( $5 \mathrm{mg}$ per $\mathrm{kg}$ body weight) was considered abnormal. By this criterion, 24 of 25 subjects receiving estradiol and 4 of 6 receiving estriol showed impaired BSP disposal during steroid treatment. This impairment developed within the first week of treatment, reaching levels as high as $30 \%$ retention. When studied daily in some subjects, BSP retention was evident within 24 hours of steroid treatment. According to Hertz (4) massive intravenous infusions induced abnormal BSP disposal within hours of treatment. Impairment in BSP excretion tended to remain constant at about the level reached in the first week of estrogen administration; in some subjects the per cent BSP retention by the standard test diminished somewhat with continued hormone treatment, although it never reverted to control values until steroid was discontinued. Abnormal retention of dye invariably receded when estrogen treatment ended.

The steroid treatment schedule, per cent BSP retention, and level of serum alkaline phosphatase in the control period and at the end of the period of estrogen administration in each subject are shown in Table I. These data, which are graphically represented in Figure 1, demonstrate that pronounced impairment in BSP disposal frequently occurred in the absence of significant alteration in serum alkaline phosphatase; elevated enzyme levels, however, were not observed unless there was concurrent abnormal BSP retention. Figures 2 and 3 show specific examples of the impairment in BSP disposal induced by small amounts of estradiol and estriol in 4 subjects.

In order to define this estrogen effect in more detail, the methods of Wheeler and associates (2, 3 ) were employed to determine the hepatic secretory $\mathrm{Tm}$ and hepatic relative storage space (S) for BSP during control and estradiol periods in 6 subjects. These methods and their application to studies of BSP metabolism have been described in detail $(2,3)$ and will not be reviewed here. 
The values for hepatic secretory $T m$ and hepatic relative storage space for BSP during control and estradiol periods in each patient are recorded in Table II.

BSP components in plasma obtained during comparable (i.e., plasma sampled at the same time in the same portion of the injection sequence) infusion periods were examined chromatographically $(10,16,17)$ in 4 subjects as follows: $2 \mathrm{ml}$ of plasma was extracted with approximately $10 \mathrm{ml}$ acetone; the extract was dried in vacuo; the residue was redissolved in $0.5 \mathrm{ml}$ distilled water, applied to a $5-\mathrm{cm}$ strip on Whatman 1 paper, and chromatographed for approximately 16 hours in a descending system containing glacial acetic acid, water, and $N$-propanol $(1: 5: 10)$. After chromatography, BSP compounds on the chromatogram were identified by exposure to ammonia fumes, appropriate areas were marked and eluted, and the BSP compounds were quantitated at $\mathbf{5 8 0}$ $\mathrm{m} \mu$ in alkaline buffer in a Beckman DU spectrophotometer. The proportions of free and conjugated BSP were determined by the relation of the individual to the combined optical densities and are reported for 4 subjects to the nearest whole figure in Table III. The assumption was made

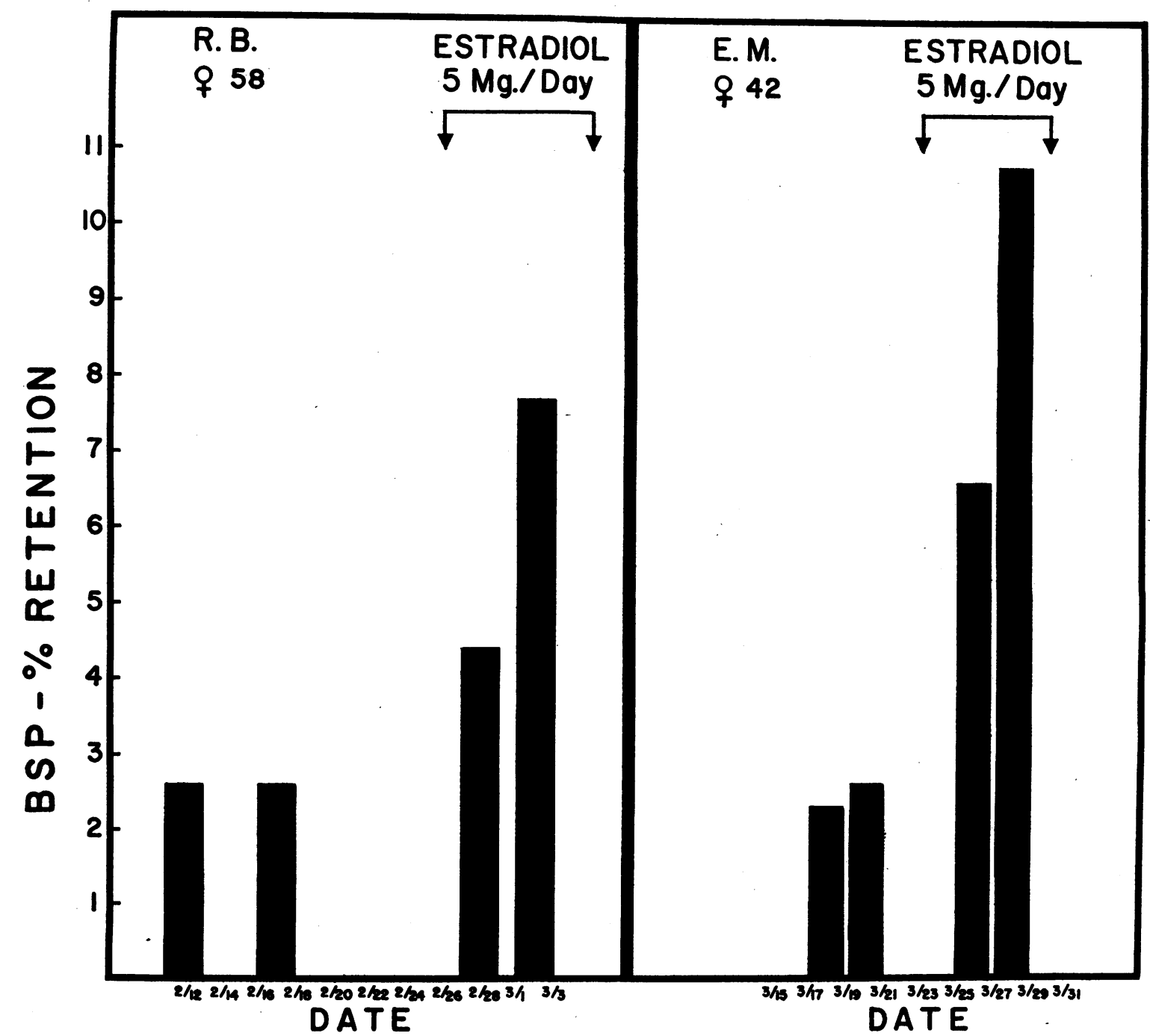

Fig. 2. EfFEcts of ESTRAdiol on BSP RETENTION IN 2 SUBJECTS RECEIVING 5 Mg PER DAY FOR 6 DAYS (R.B., TESTS on DAYS 2 AND 5) AND 7 . DAYs (E.M., TESTS on DAYs 2 AND 4). Pretreatment BSP tests are shown on the left in each graph. 


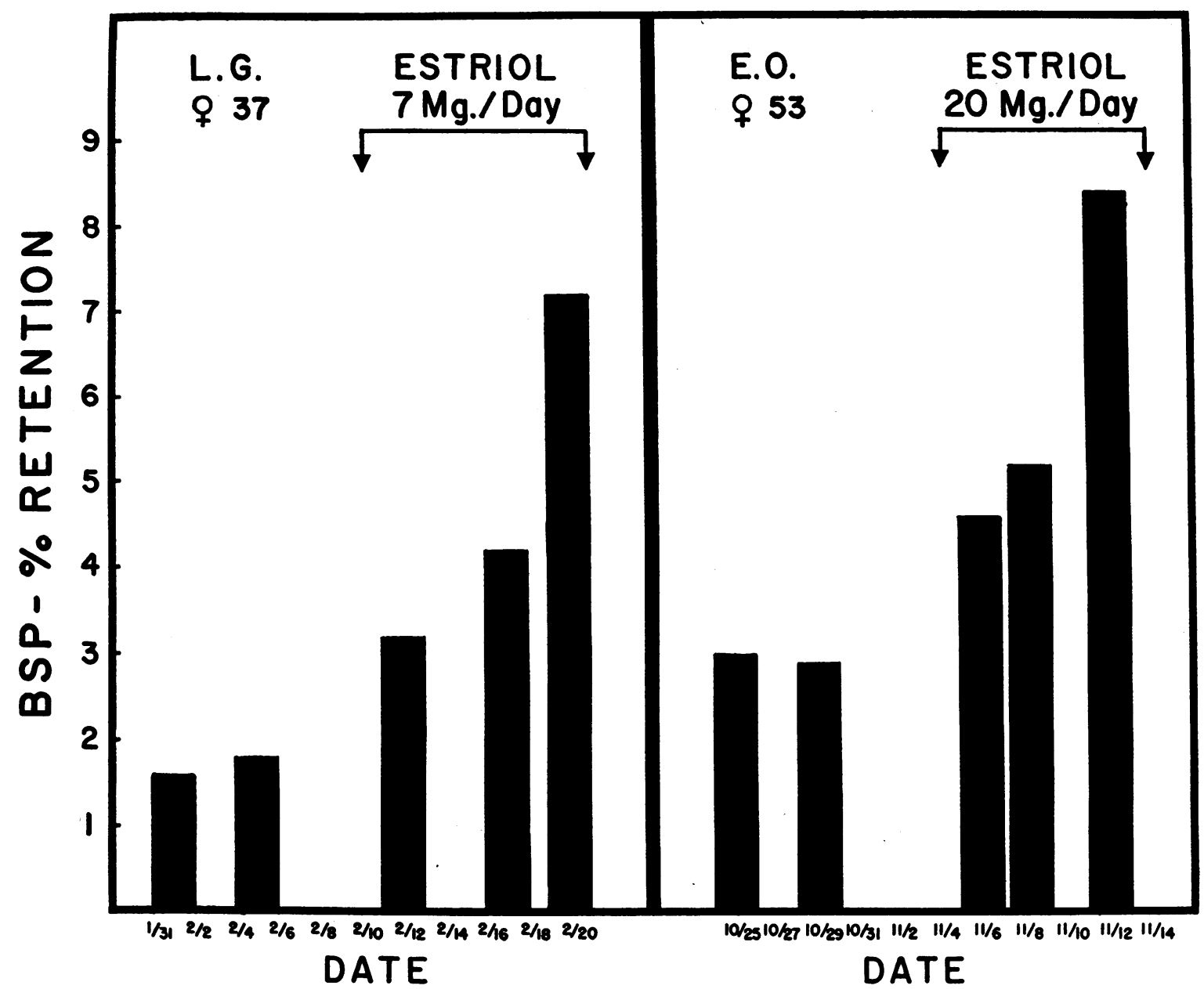

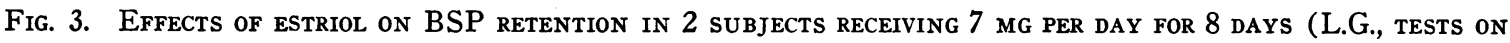
DAYS 2, 6, AND 8) AND 20 Mg PER DAY FOR 8 DAYs (E.O., TESTS on DAys 2, 4, AND 8). Pretreatment BSP tests are shown on the left in each graph.

TABLE II

Plasma retention (45 minutes), hepatic secretory transport maximum $\left(T_{m}\right)$, and hepatic relative storage space $(S)$ for BSP in 6 patients during control and estrogen-treatment periods

\begin{tabular}{|c|c|c|c|c|c|c|c|}
\hline \multirow[b]{2}{*}{ Patient } & \multirow[b]{2}{*}{ Treatment } & \multicolumn{2}{|c|}{$\begin{array}{c}\text { Plasma retention } \\
\text { at } 45 \text { minutes } \\
\end{array}$} & \multicolumn{2}{|c|}{$\mathrm{Tm}$} & \multicolumn{2}{|c|}{$\mathbf{s}$} \\
\hline & & Control & Estrogen & Control & Estrogen & Control & Estrogen \\
\hline \multirow{7}{*}{$\begin{array}{l}\text { C.T. } \\
\text { B.P. } \\
\text { D.H. } \\
\text { C.M. } \\
\text { E.K. } \\
\text { V.S. }\end{array}$} & \multirow{7}{*}{$\begin{array}{l}\text { Estradiol, } 50 \mathrm{mg} / \text { day } \\
\text { for } 5 \text { days } \\
\text { Estradiol, } 150 \mathrm{mg} / \text { day } \\
\quad \text { for } 5 \text { days } \\
\text { Estradiol, } 50 \mathrm{mg} / \text { day } \\
\quad \text { for } 17 \text { days } \\
\text { Estradiol, } 100 \mathrm{mg} / \text { day } \\
\quad \text { for } 7 \text { days } \\
\text { Estradiol, } 100 \mathrm{mg} / \text { day } \\
\text { for } 11 \text { days } \\
\text { Estradiol, } 100 \mathrm{mg} / \text { day } \\
\quad \text { for } 11 \text { days }\end{array}$} & \multicolumn{2}{|c|}{$\%$} & \multicolumn{2}{|c|}{$\mathrm{mg} / \min$} & \multicolumn{2}{|c|}{$\mathrm{mg} / \mathrm{mg} / 100 \mathrm{ml}$} \\
\hline & & 3.9 & 9.4 & 8.70 & 2.57 & 131.5 & 108.0 \\
\hline & & 2.0 & 14.1 & 7.60 & 2.55 & 54.6 & 40.5 \\
\hline & & 3.1 & 11.0 & 6.15 & 2.70 & 58.5 & 117.5 \\
\hline & & 2.8 & 10.2 & 6.50 & 0.34 & 37.8 & 77.6 \\
\hline & & 3.6 & 17.2 & 6.60 & 4.05 & 54.2 & 68.0 \\
\hline & & 3.4 & 13.3 & 6.40 & 2.55 & 27.5 & 58.7 \\
\hline
\end{tabular}


TABLE III

Chromatographic analysis of BSP compounds in plasma

\begin{tabular}{cccccc}
\hline & \multicolumn{2}{c}{ Control period } & & \multicolumn{2}{c}{ Estrogen period } \\
\cline { 5 - 6 } Patient & $\%$ & $\%$ & & $\%$ & $\%$ \\
& Free & Conjugated & & Free & Conjugated \\
C.T. & 94 & 6 & & 80 & 20 \\
B.P. & 93 & 7 & & 50 & 50 \\
D.H. & 85 & 15 & & 57 & 43 \\
C.M. & 85 & 15 & & 40 & 60 \\
\hline
\end{tabular}

that the chromatographic losses and optical densities of free and conjugated BSP were equal (17). The developed chromatograms from control and estradiol periods in 1 of the 4 subjects are shown in Figure 4. The three trailing BSP bands shown were Ninhydrin positive. Three conjugates were not detected in all 4 subjects, but the number observed during control and estrogen periods in each case was always equal.

Percutaneous biopsies of the liver were obtained during control periods and at the end of 17 to 39 days of treatment with 50 to $200 \mathrm{mg}$ per day of estradiol in 6 patients undergoing intensive experimental therapy with this hormone. Tissue samples were fixed in formalin, stained with hematoxylin and eosin, for iron and for fibrous tissue (Mallory), and examined by light microscopy. Liver biopsy was normal in 2 subjects in both control and estrogen periods. The remaining sub-

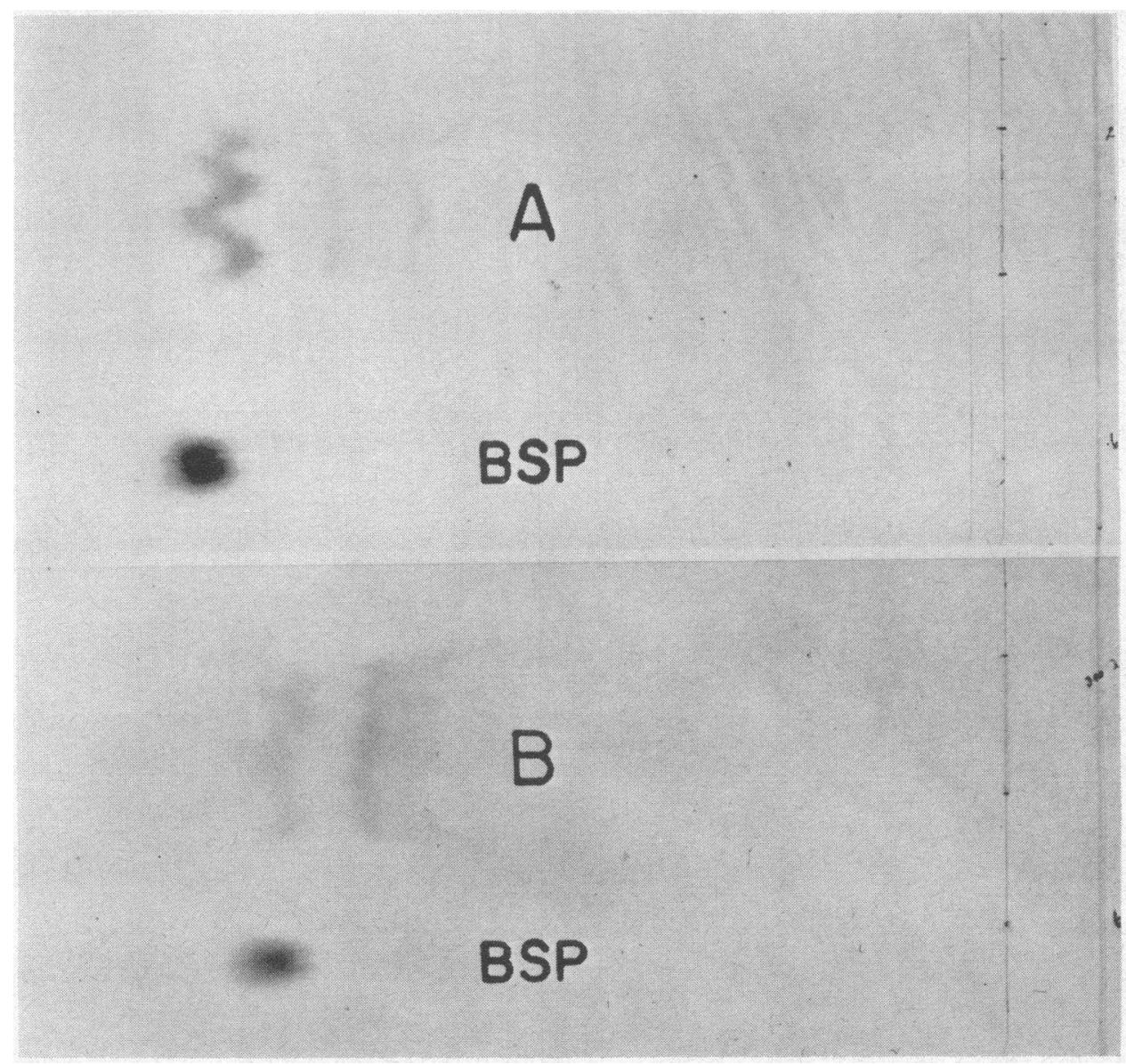

Fig. 4. Developed (AMmonia Vapor) chromatograms of BSP COMPounds in plasma DURING COMPARABLE BSP INFUSIONS BEFORE (A) AND AFTER (B) ESTROGEN TREATMENT IN ONE PATIENT. Origins are at the right; standard BSP spots are labeled. In the control period (A), a heavy free BSP and three trailing lighter BSP bands can be seen; the three trailing bands were Ninhydrin positive. In the estrogen period (B) all four BSP components are also evident. 
jects had a variety of nonspecific or slight changes during control periods, consisting of mild hemosiderosis, slight "reactive" and fatty changes, minimal proliferation of Kupfer cells, and so forth. No significant alteration in these hepatic findings was induced by the estrogen treatment described; specifically, bile casts were not seen and biliary canaliculi remained inconspicuous. Electron microscopic examination of biopsy samples was not available at the time of these studies.

\section{Discussion}

This study demonstrates that the natural estrogen, estradiol, impairs hepatic excretory capacity for the dye BSP in man. After administration of this hormone abnormal BSP retention, as determined by the standard single injection tests, developed rapidly and persisted as long as hormone injections continued. Hepatic disposal of BSP reverted to normal when estradiol treatment ended; the rate of recovery of hepatic excretory capacity for this dye is not known with certainty, although it is probably relatively rapid. This may be adduced from the fact that BSP tests became normal in all subjects 1 to 4 weeks after estrogen treatment was stopped despite the administration of large amounts of steroid in an injection vehicle from which delayed absorption could be anticipated. The only other index of hepatic function significantly altered by estrogens in this study was the serum alkaline phosphatase, which was increased to abnormal levels in approximately $50 \%$ of steroid-treated subjects. Other serum enzyme activities indicative of direct hepatocellular damage remained unaltered, and BSP retention, as noted, developed in many subjects in whom no change in serum alkaline phosphatase occurred. Estriol, an in vivo transformation product of estradiol, also impaired hepatic excretory capacity for BSP in man. No attempt was made to compare the relative potency of estradiol and estriol with respect to this action. It is evident from these studies and those of Hertz (vide supra) that this biological property probably characterizes a variety of C-18 steroids of physiologic and synthetic origin.

Determination of the hepatic secretory $\mathrm{Tm}$ and hepatic relative storage space for BSP according to the methods of Wheeler and associates coupled with chromatographic analysis of the amounts of free and conjugated dye in plasma provides a quantitative description of the hepatic processes concerned with BSP metabolism $(2,3,6,10,16-22)$. By inference, such data also provide information on the probable site of action of substances affecting disposition of this dye. Hepatic relative storage space for BSP did not alter in a consistent fashion during estrogen administration; there was, nevertheless, a tendency for the value of $S$ to increase, and this was occasionally pronounced. Hepatic secretory $\mathrm{Tm}$ for this dye, however, was markedly depressed in all subjects after hormone treatment; in 1 subject hepatic Tm decreased nearly 95\% reaching a level in the estradiol period within the range observed in patients with congenital disorders of hepatic excretory function such as the Dubin-Johnson syndrome (3). Chromatographic analysis of BSP compounds in plasma revealed uniformly higher levels of conjugated BSP during estrogen administration as compared with control periods, thus discounting major hormonal impairment of conjugation processes for this dye or of transfer of dye from sinusoid to hepatocyte (although these data do not entirely exclude some estrogen action on these processes). It is reasonable to infer therefore that the alteration in hepatic excretory capacity for BSP which is induced by estrogens is attributable largely to defective transport of BSP compounds across hepatocyte membrane bordering canalicular spaces where excretion takes place. The hepatic Tm calculated by these techniques is a composite figure that represents an average of the transport maxima for the several BSP components that have been identified (3); it is possible that estrogens impair hepatic transport of each of these compounds to a different degree.

Failure of estradiol and estriol to induce hyperbilirubinemia in these studies is of interest and may be attributable to the magnitude of the excretory $\mathrm{Tm}$ for this substance (23); it does not imply that capacity of the liver for disposal of this pigment remains intact during such treatment, since defects in hepatic disposal of bilirubin may be demonstrable only with appropriate infusion studies as Soffer has shown in pregnant women (24) [and as Combes and associates (6) have shown for BSP]. Similarly the absence, by light microscopy, of overt alterations in hepatic paren- 
chyma during intensive estrogen treatment does not preclude demonstration, with appropriate histochemical and electron microscopic techniques, of the hepatocellular changes described by others in patients and experimental animals treated with synthetic steroids that induce similar defects in hepatic function (25-28).

These data define a new biological property of natural estrogens and indicate that the liver may be, especially in pregnancy, an important site of action of these hormones in man. Together with the observations of Hertz (vide supra) they also demonstrate that impairment of hepatic excretory function is a steroid hormone action which is not restricted solely to synthetic compounds of unnatural configuration such as methyl testosterone, $17 \alpha$-ethyl-19-nortestosterone, 9-fluoro-11 $\beta$ hydroxymethyl testosterone, and related substances (29-33).

The amounts of estradiol administered to most patients in this investigation considerably exceeded those secreted in the gravid state, although not all amounts (Table I) exceeded the total daily output of estrogenic steroids in pregnancy (34-36) ; however, no attempt was made to determine either the minimal dose of estradiol required to impair BSP excretion or the influence of chronic administration of physiologic doses of hormone on this index of liver function in man. Moreover, the doses of estriol used in this study were in fact well within the amounts of this specific metabolite produced during the last trimester of normal human pregnancy $(34,36)$; consideration of the potential clinical relevance of these observations is therefore warranted.

Although standard texts still suggest that pregnancy does not alter hepatic function in humans, elevation of serum levels of alkaline phosphatase is common during the last trimester $(37-40)$; delayed disappearance of infused bilirubin during this period has been demonstrated (24); standard BSP tests may be abnormal at this time $(41,42)$; and, as Combes and associates (6) have shown recently, the hepatic secretory $\mathrm{Tm}$ for BSP is significantly lower in gravid as compared to normal women. Hepatic Tm for the dye rapidly reverts to normal in the postpartum period, and these authors have suggested that impaired hepatic disposition of BSP is mediated by the increased hormonal levels of pregnancy (6). The results of the present study are consistent with this view and indicate that estrogens in particular may account wholly, or in part, for the maternal hepatic functional alterations described. The possibility that progesterone may modify this estrogen action in pregnancy merits examination; in preliminary studies from this laboratory pharmacological amounts of this C-21 steroid alone have failed to alter the hepatic Tm for BSP in humans.

It has also been known for some time that premature as well as normal infants have impaired excretory capacity for BSP in the neonatal period (7-9). Oppé and Gibbs (9) have shown that the most marked abnormality in plasma disappearance curves of BSP in the newborn occurs in the second or excretory phase [as in the DubinJohnson syndrome (43)] and that recovery of hepatic capacity for disposal of the dye occurs rapidly, regardless of the gestational age or birth weight of the infant. BSP-glutathione conjugating enzyme activity in fetal and neonatal rats and in maternal rats at term is low according to the studies of Combes and Stakelum (10), who have suggested that delayed BSP clearance in neonatal children may be due in part to inadequate development of this conjugating system. From other studies in newborn and older children Vest (44) concluded that this delay was caused primarily by impairment of the secretory mechanism for the dye. The human fetus is exposed to extremely high levels [approximately 5 to 10 times maternal blood levels (45)] of estrogens, particularly estriol $(34,36)$, near term. This fact, in light of the data reported here, suggests that impaired excretory capacity for BSP in the neonatal period may represent, in part, a residual effect of the intense hepatic exposure to these hormones in utero.

The relation of this estrogen action to disorders of liver function apart from the maternalfetal excretory impairments noted is speculative, since it is not known whether this effect in man is self-limited, leads to morphological changes, or predisposes the liver to injury from otherwise innocuous processes. It may prove fruitful, however, to consider the possibility that endogenous hormones of this type or their transformation products (12) might have some relation to the apparent severity of hepatitis in pregnancy (46-48) or the high female incidence of posthepatitis cir- 
rhosis (49-52) and hepatotoxic drug reactions (53).

\section{Summary}

The influence of natural estrogens on hepatic function was studied in 31 patients by conventional tests, BSP infusions, and percutaneous biopsy. Estradiol and estriol rapidly and almost invariably impaired hepatic excretory capacity for the dye sulfobromophthalein (BSP) in man; this impairment was accompanied by elevations in alkaline phosphatase in some patients, but other hepatic function tests as well as liver biopsy specimens examined by light microscopy remained normal despite intensive estrogen treatment. Estradiol markedly depressed hepatic secretory transport $(\mathrm{Tm})$ for BSP; the hepatic relative storage space (S) for dye tended to increase although the effect was not consistent. Chromatographic analyses of plasma BSP components showed increased levels of conjugated BSP in estrogen as compared with control periods. The data are consistent with impaired transfer of dye compounds from hepatocyte to canalicular spaces during estrogen treatment. This biological action of natural estrogens probably accounts in part for the maternal-fetal impairments in BSP disposal that characterize pregnancy and the neonatal period.

\section{Acknowledgments}

We express our appreciation to Mrs. Genevieve LaPinska and Mrs. Frances J. Skozen for preparation of the manuscript.

\section{References}

1. Mueller, M. N., and A. Kappas. Impairment of hepatic excretion of sulfobromophthalein (BSP) by natural estrogens. Trans. Ass. Amer. Phycns 1964,77 , in press.

2. Wheeler, H. O., R. M. Epstein, R. R. Robinson, and E. S. Snell. Hepatic storage and excretion of sulfobromophthalein sodium in the dog. J. clin. Invest. 1960, 39, 236.

3. Wheeler, H. O., J. I. Meltzer, and S. E. Bradley. Biliary transport and hepatic storage of sulfobromophthalein sodium in the unanesthetized dog, in normal man, and in patients with hepatic disease. J. clin. Invest. 1960, 39, 1131.

4. Hertz, R. Personal communication, 1964.

5. Huggins, C., and F. Yao. Influence of hormones on liver. I. Effects of steroids and thyroxine on pyridine nucleotide-linked dehydrogenases. J. exp. Med. 1959, 110, 899.
6. Combes, B., H. Shibata, R. Adams, B. D. Mitchell, and V. Trammell. Alterations in sulfobromophthalein sodium-removal mechanisms from blood during normal pregnancy. J. clin. Invest. 1963, 42, 1431.

7. Herlitz, C. W. Rosenthal und White's Leberfunktionsprobe (bromsulphaleinprobe) bei Kindern unter einem Jahr und besonders bei Ikterus neonatorum. Acta paediat. (Uppsala) 1927, 6, 214.

8. Obrinsky, W., M. L. Denley, and R. W. Brauer. Sulfobromophthalein sodium excretion test as a measure of liver function in premature infants. Pediatrics 1952, 9, 421.

9. Oppé, T. E., and I. E. Gibbs. Sulphobromophthalein excretion in premature infants. Arch. Dis. Childh. 1959, 34, 125.

10. Combes, B., and G. S. Stakelum. Maturation of the sulfobromophthalein sodium-glutathione conjugating system in rat liver. J. clin. Invest. 1962, 41, 750.

11. Kappas, A., H. E. H. Jones, and I. M. Roitt. Effects of steroid sex hormones on immunological phenomena. Nature (Lond.) 1963, 198, 902.

12. Kappas, A., and R. H. Palmer. Selected aspects of steroid pharmacology. Pharmacol. Rev. 1963, 15, 123

13. Mueller, M. N., and A. Kappas. Sex hormones in experimental and human arthritis. Proc. Inst. Med. Chic. 1963, 24, 303.

14. Davis, K. J., and P. M. Jenner. Toxicity of three drug solvents. Toxicol. appl. Pharmacol. 1959, 1, 576.

15. Horn, H. J. Toxicology of dimethylacetamide. Toxicol. appl. Pharmacol. 1961, 3, 12.

16. Carbone, J. V., G. M. Grodsky, and V. Hjelte. Effect of hepatic dysfunction on circulating levels of sulfobromophthalein and its metabolites. J. clin. Invest. 1959, 38, 1989.

17. Combes, B. The biliary excretion of sulfobromophthalein sodium (BSP) in the rat as a conjugate of glycine and glutamic acid. J. clin. Invest. 1959, 38, 1426.

18. Krebs, J. S., and R. W. Brauer. Metabolism of sulfobromophthalein sodium (BSP) in the rat. Amer. J. Physiol. 1958, 194, 37.

19. Combes, B., H. O. Wheeler, A. W. Childs, and S. E. Bradley. The mechanism of bromsulfalein removal from the blood. Trans. Ass. Amer. Phycns 1956, 69, 276.

20. Meltzer, J. I., H. O. Wheeler, and W. I. Cranston. Metabolism of sulfobromophthalein sodium (BSP) in dog and man. Proc. Soc. exp. Biol. (N. Y.) 1959, 100, 174.

21. Grodsky, G. M., J. V. Carbone, and R. Fanska. Identification of metabolites of sulfobromophthalein. J. clin. Invest. 1959, 38, 1981.

22. Javitt, N. B., H. O. Wheeler, K. J. Baker, O. L. Ramos, and S. E. Bradley. The intrahepatic con- 
jugation of sulfobromphthalein and glutathione in the dog. J. clin. Invest. 1960, 39, 1570.

23. Arias, I. M. Effects of a plant acid (Icterogenin) and certain anabolic steroids on the hepatic metabolism of bilirubin and sulfobromophthalein (BSP). Ann. N. Y. Acad. Sci. 1963, 104, 1014.

24. Soffer, L. J. Bilirubin excretion as a test for liver function during normal pregnancy. Bull. Johns Hopk. Hosp. 1933, 52, 365.

25. Novikoff, A. B., and E. Essner. The liver cell. Some new approaches to its study. Amer. J. Med. 1960, 29, 102.

26. Goldfischer, S., I. M. Arias, E. Essner, and A. B. Novikoff. Cytochemical and electron microscopic studies of rat liver with reduced capacity to transport conjugated bilirubin. J. exp. Med. 1962, 115, 467.

27. Schaffner, F., H. Popper, and V. Perez. Changes in bile canaliculi produced by norethandrolone: electron microscopic study of human and rat liver. J. Lab. clin. Med. 1960, 56, 623.

28. Popper, H., and F. Schaffner. Fine structural changes of the liver. Ann. intern. Med. 1963, 59, 674.

29. Heaney, R. P., and G. D. Whedon. Impairment of hepatic bromsulphalein clearance by two 17-substituted testosterones. J. Lab. clin. Med. 1958, 52, 169.

30. Kory, R. C., M. H. Bradley, R. N. Watson, R. Callahan, and B. J. Peters. A six-month evaluation of an anabolic drug, norethandrolone, in underweight persons. II. Bromsulfalein (BSP) retention and liver function. Amer. J. Med. 1959, 26, 243.

31. Leevy, C. M., G. R. Cherrick, and C. S. Davidson. Observations on norethandrolone-induced abnormalities in plasma decay of sulfobromophthalein and indocyanine green. J. Lab. clin. Med. 1961, 57, 918.

32. Marquardt, G. H., C. I. Fisher, P. Levy, and R. M. Dowben. Effect of anabolic steroids on liver function tests and creatine excretion. J. Amer. med. Ass. 1961, 175, 851.

33. Scherb, J., M. Kirschner, and I. Arias. Studies of hepatic excretory function. The effect of $17 \alpha-$ ethyl-19-nortestosterone on sulfobromphthalein sodium (BSP) metabolism in man. J. clin. Invest. 1963, 42, 404.

34. Fishman, J., J. B. Brown, L. Hellman, B. Zumoff, and T. F. Gallagher. Estrogen metabolism in normal and pregnant women. J. biol. Chem. 1962, 237, 1489.

35. Gurpide, E., M. Angers, R. L. Vande Wiele, and S. Lieberman. Determination of secretory rates of estrogens in pregnant and nonpregnant women from the specific activities of urinary metabolites. J. clin. Endocr. 1962, 22, 935.

36. Yousem, H. L., and D. Strummer. Simple gas chromatographic method for estimation of urinary es- triol in pregnant women. Amer. J. Obstet. Gynec. 1964, 88, 375.

37. Bodansky, M. Changes in serum calcium, inorganic phosphate and phosphatase activity in the pregnant woman. Amer. J. clin. Path. 1939, 9, 36.

38. Speert, H., S. Graff, and A. M. Graff. Serum phosphatase relations in mother and fetus. Amer. J. Obstet. Gynec. 1950, 59, 148.

39. Thorling, L. Jaundice in pregnancy. A clinical study. Acta med. scand. 1955 (suppl. 302), 151, 1.

40. McNair, R. D., and R. V. Jaynes. Alterations in liver function during normal pregnancy. Amer. J. Obstet. Gynec. 1960, 80, 500.

41. Christhilf, S. M., and R. W. Bonsnes. Liver function during pregnancy and puerperium, as measured by the cephalin-cholesterol flocculation, the thymol turbidity, and the bromsulfalein tests. Amer. J. Obstet. Gynec. 1950, 59, 1100.

42. Lichtman, S. S. Diseases of the Liver, Gallbladder and Bile Ducts. Philadelphia, Lea \& Febiger, 1953, p. 947.

43. Mandema, E., W. H. de Fraiture, H. O. Nieweg, and A. Arends. Familial chronic idiopathic jaundice (Dubin-Sprinz disease), with a note on bromsulphalein metabolism in this disease. Amer. J. Med. 1960, 28, 42.

44. Vest, M. F. Conjugation of sulfobromophthalein in newborn infants and children. J. clin. Invest. 1962, 41, 1013.

45. Maner, F. D., B. D. Saffan, R. A. Wiggins, J. D. Thompson, and J. R. K. Preedy. Interrelationship of estrogen concentrations in the maternal circulation, fetal circulation and maternal urine in late pregnancy. J. clin. Endocr. 1963, 23, 445.

46. Mickal, A. Infectious hepatitis in pregnancy. Amer. J. Obstet. Gynec. 1951, 62, 409.

47. Long, J. S., H. Boysen, and F. O. Priest. Infectious hepatitis and pregnancy. Amer. J. Obstet. Gynec. 1955, 70, 282.

48. Ober, W. B., and P. M. LeCompte. Acute fatty metamorphosis of the liver associated with pregnancy. A distinctive lesion. Amer. J. Med. 1955, $19,743$.

49. Bearn, A. G., H. G. Kunkel, and R. J. Slater. The problem of chronic liver disease in young women. Amer. J. Med. 1956, 21, 3.

50. Klatskin, G. Subacute hepatic necrosis and postnecrotic cirrhosis due to anicteric infections with the hepatitis virus. Amer. J. Med. 1958, 25, 333.

51. Willocx, R. G., and K. J. Isselbacher. Chronic liver disease in young people. Clinical features and course in thirty-three patients. Amer. J. Med. 1961, 30, 185.

52. Tisdale, W. A. Subacute hepatitis. New Engl. J. Med. 1963, 268, 138.

53. Klatskin, G. Discussion (p. 785) in Iatrogenically induced liver disease. Bull. N. Y. Acad. Med. 1961, $37,767$. 